\title{
Patient Participation in Cancer Network Governance: A Six-year Case Study
}

\section{Dominique Tremblay ( $\nabla$ dominique.tremblay2@usherbrooke.ca )}

Universite de Sherbrooke https://orcid.org/0000-0002-1798-5681

\section{Nassera Touati}

École nationale d'administration publique

\section{Susan Usher}

École nationale d'administration publique

\section{Karine Bilodeau}

Universite de Montreal Faculte des sciences infirmieres

\section{Marie-Pascale Pomey}

Universite de Montreal

\section{Lise Lévesque}

Universite de Sherbrooke - Campus de Longueuil

\section{Research article}

Keywords: Patient participation, cancer, networks, governance functions, collaborative governance, case study, qualitative data

Posted Date: September 21st, 2020

DOI: https://doi.org/10.21203/rs.3.rs-51127/v1

License: (9) (i) This work is licensed under a Creative Commons Attribution 4.0 International License. Read Full License

Version of Record: A version of this preprint was published at BMC Health Services Research on September 7th, 2021. See the published version at https://doi.org/10.1186/s12913-021-06834-1. 


\section{Abstract}

Background: Patient participation in decision-making has become a hallmark of responsive healthcare systems. Cancer programs in many countries have formally committed to involving people living with and beyond cancer (PLC) at multiple levels of network-based services. However, PLC participation in the governance of these networks remains highly variable for reasons that are, as yet, poorly understood. This study explores how PLC participation takes shape within cancer network governance.

Methods: This case study, using a qualitative approach in a natural setting, aimed to identify mechanisms that enable PLC participation in governance. It was conducted over six years in four local cancer networks in Québec (Canada), where PLC representation was prescribed by the Cancer Directorate. Data were collected from documents, meeting observations, and interviews with actors $(n=89)$ involved in national and local cancer governance committees: policymakers, managers, clinicians and PLC. These data were triangulated and iteratively analysed according to a framework based on functions of collaborative governance in the network context.

Results: Main mechanisms enabling PLC participation are: 1) emphasis on patient-centred care as a network objective; 2) opportunities to shape mandated PLC representation into participation; and 3) recognition of PLC knowledge in decision-making. The shared vision of person-centred care facilitates PLC participation. The quality of participation improves through changes in how committee meetings are conducted, and through the establishment of a national forum in which PLC pool their experience, develop skills and establish a common voice on priority issues. PLC knowledge is especially valued around particular challenges such as designing integrated care trajectories and overcoming barriers to accessing care. These three mechanisms interact to enable PLC participation in governance and are activated to varying extents in each local network context.

Conclusions: This study reveals that mandating PLC representation on governance structures is a powerful context element enabling participation, but that it also delineates which governance functions are open to influence from PLC participation. While the activation of mechanisms is context dependent, the insights from this study in Québec are transferable to cancer networks in other jurisdictions seeking to embed PLC participation in decision-making.

\section{Background}

The participation of people living with and beyond cancer (PLC) is emphasized in many countries to guide the delivery and improvement of cancer care (1-4). The literature suggests that patient participation in decision-making can provide a unique $360^{\circ}$ view of care processes and encourage collaboration $(5,6)$, notably by breaking down hierarchical barriers among providers $(7,8)$ as well as between providers and PLC (9). Participation manifests concretely in a variety of activities that enable mutual exchange of experience and knowledge between patients (and/or families or patient associations) and healthcare providers to shape health and social care services (10). 
In this general trend, the province of Quebec, Canada is no exception. Its national cancer plan describes a network (national) of networks (local) as the overall organisational model, in which PLC participation is promoted at all levels: clinical (individual care decision-making), organisational (cancer service planning, delivery and evaluation, healthcare professional training; research) and policy (national cancer plan) (11). The model reflects a widespread move toward network-based cancer services in which person-centred care is a core principle for quality care $(12,13)$. The Quebec network is prescribed by policymakers at national level, and is operationalized at organisational and clinical level. In practice, networks take shape as various groups of goal-oriented interdependent but autonomous actors (individuals or organisations) that produce a collective output (14). Network-based working is suited to addressing "wicked problems" (15) that cannot be 'solved' or even formulated in a definitive way. While wicked problems increase pressure for coordination, network dynamics intensify uncertainty and pose governance challenges (16). There is some evidence that patient participation can enhance healthcare governance (7), and recent interest in patient influence on governance in the network context (17), but little evidence about how to enable participation in the particular area of cancer. The main objective of this study is to explore how PLC participation takes shape within cancer network governance.

PLC participation in governance has been formalized at both national and local level within the Quebec cancer network, as depicted in Fig. 1. At the local level, Organization Coordinating Committees with medical and administrative co-leadership are meant to include PLC along with professional, medical, public health and non-profit service providers involved in the cancer trajectory. At national level, two PLC participate alongside medical and administrative representatives from each local organization in a National Coordinating Committee. This last oversees the Quebec cancer network and is led by the Cancer Care Directorate, one of multiple branches within the Ministry of Health and Social Services (Ministère de la Santé et des Services sociaux, MSSS). These two committees date back to 2013, while a third, the national PLC Committee, was established in 2017 to bring together, in a form of community of practice, PLC representatives from local and national coordinating committees to expand patient (and family) participation in cancer program governance processes.

\section{Conceptual framework}

This study is based on a conceptual framework constructed around functions of network governance and how they are expected to work. A classic definition of governance refers to "the conduct of collective action from a position of authority" (18). More recent definitions tend to democratise the governance of healthcare networks, regarding governance as the "roles, responsibilities and interactions among service users, government decision-makers and health service providers" (19). The coordination of complex relationships between individuals and organisations in networks is meant to enable movement from bureaucratic, siloed and rigid structures to cross-boundary learning, shared decision-making, collective capacity for action, and ultimately, care and services that are responsive to the needs of PLC (20). PLC participation in cancer network governance can be seen as part of a major shift from coordination undertaken from a unique position of authority, to a collaborative regimen (21) that fosters motivation, engagement and collective action among stakeholders with different perspectives (22). 


\section{Knowledge gaps}

Research in European cancer systems finds wide variation between countries in opportunities for PLC participation (23). A study of cancer networks in England shows that the experiential knowledge of PLC, while increasingly present, remains peripheral to the elite scientific apparatus in decision-making (24). Efforts to engage patients in defining what they need from care and opportunities for improvement are still "in their infancy" (25). The present study of the Quebec cancer network seeks to contribute to reducing these knowledge gaps. To achieve the main objective described above, it explores underlying mechanisms that enable PLC participation in - and influence on - governance functions. Denis et al (26) define five governance functions, which have been adapted to cancer care networks (27): 1) formulating a mission and vision of durable high-quality care in the network; 2) allocating resources to achieve network goals; 3 ) managing relationships to foster connections between individuals and organisations in the network; 4) managing knowledge to support cancer network integration, and 5) monitoring and control. Mechanisms refer to "underlying entities, processes, or structures which operate in particular contexts to generate outcomes of interest" (28), in this case PLC participation in governance of the Quebec cancer network.

\section{Methods}

\section{Setting: Quebec's cancer network}

The Quebec 'network of cancer networks' is a major and highly visible part of the province's publicly funded healthcare system. The network structure is a key component of the National Cancer Plan, launched in 1998 and updated in 2013 to coordinate the organisation and delivery of integrated care. A Cancer Directorate within the MSSS prescribes cancer network governance structures. The national and local committees shown in Figure 1 form the governance structures to pursue network-based working. In 2017, the Cancer Directorate published a framework for partnering with PLC, specifying that local committees were expected to recruit PLC (preferably more than one), assure training and support, equip them with documentation needed to participate in committee deliberations and reserve a dedicated item on the meeting agenda for PLC contributions (29). However, PLC participation has been variable between the different local organisation committees, and gaps persist between the vision prescribed by the Cancer Care Directorate and practice across the network.

\section{Study design}

The case study design was chosen considering that patient participation and network governance in cancer care remain empirically understudied and poorly understood. The study was conducted over six years (2014 to 2020), in line with our objective to discern patterns of meaning that help understand phenomena in their natural setting (30), in our case underlying mechanisms that enable PLC participation in, and influence on, governance functions. 
The case involved four local cancer networks, reflecting the multiple realities seen across the Quebec cancer network in terms of population, territory, urban/rural context, academic or community mission, time since local cancer network implementation, and range of cancer services offered locally (27). Variation was sought to enlarge the perspective of the phenomenon in context and increase the credibility and reliability of findings (30). Approval was received from the Ethics Board Committee (MP-HCLM-14-010; MP-04-2019316) and all participants signed an informed consent form.

\section{Data collection}

Qualitative data from multiple sources (documents, meeting observation, individual and focus groups) were triangulated (30) to identify mechanisms that enable PLC participation in network governance, as seen from multiple perspectives across local and national levels. A systematic interview grid was built around governance functions (26) and collaborative regimes (21). Interview participants were members of the national cancer network committee and members of local network committees ( $\mathrm{n}$ total $=89$ ), selected through purposeful sampling (31): policymakers $(n=17)$, managers $(n=15)$, clinician-managers $(n=19)$, clinicians $(n=19)$, and PLC $(n=19)$. For data collection from PLC on local committees, focus groups were conducted instead of individual interviews. This enabled researchers to benefit from a range of perspectives and animated exchange among PLC, whose experience on these committees was of highly variable duration. (See Additional file 1 for focus group discussion guide and interview guide.) All interviews and focus group discussions were audio recorded, transcribed and anonymized. Documents $(\mathrm{n}$ total $=569)$ from national and local cancer programs included organisational charts, minutes of meetings and notes from non-participant observation of meetings $(n=112)$. All data were integrated into a database and managed with QDA Miner ${ }^{\mathrm{TM}}$ software (32).

Data were analysed to identify dynamic mechanisms in context that enabled PLC participation at different levels of governance in the cancer network. An iterative content analysis approach was used. Structural coding based on the interview guide was followed by thematic coding (33). To ensure coding reliability, data sources were triangulated, co-authors explored differences and refined codes, and study context was detailed to enable assessment of the transferability of findings (34). The COREQ (35) checklist was used to assure the quality of data collection and analysis in this qualitative study (see Additional file 2).

\section{Results}

In line with the specific study objectives, findings across local and national levels highlight three main mechanisms as especially important to enabling PLC participation in network governance functions: emphasis on patient-centred care as a network objective, shaping opportunities for efforts to strengthen PLC contributions within prescribed spaces, and recognition of the distinct knowledge of PLC in decisionmaking processes. Conditions enabling the activation of these mechanisms to influence governance functions relate primarily to network structure. The MSSS as lead organisation encourages a distributed and collective approach to some, but not all, governance functions. Resource allocation and monitoring 


\section{Mechanism 1) Emphasis on patient-centred care as a network objective}

Quebec's national cancer plan (11) clearly expresses patient-centred care (PCC) as a core value, and the spread of this value is evident in the policies that structure the network at various levels. PCC appears, among study participants at national and local level, as a convergence point coherent with both the clinician's duty to respond to the individual needs of PLC and the organisation's mandate to ensure responsiveness to whole person needs.

"We used to speak of continuous improvement in administrative terms to clinicians and that did not get through to them, not at all. Then we changed our discourse, saying: "What we all want is to improve services for the patient, to respond to patient needs, at the right time, for the right person." When we talk that way, we reach everyone" (manager, local level).

The emphasis on PCC facilitated acceptance of PLC participation to guide decision-making within the network. Some informants noted a shift in organisational culture and discourse that promoted collaboration and helped defuse conflict around where services should be located and the roles of different providers.

"The focus on patient experience forced us as a community to work on concerted action" (clinical manager, local level).

"When a PLC is at the table, committee decisions are made in terms of access to quality care. If the PLC is not there, debate can get caught up in concerns such as the status of the establishment or making things easier for providers" (clinical manager, national level).

On committees, PLC embodied the idea of PCC as well as clarifying what it meant in particular contexts, thereby participating in the governance function of shaping network vision. PLC input emphasized a broader view of cancer care that includes the survivorship course, primary care and community support services, moving from a perspective of "conquering cancer" to "living with and beyond cancer" as a chronic disease. It also widened the spectrum of relevant services and "reveal[s] gaps between patient and provider perceptions of what constitutes good care" (clinician manager, local level). With respect to wait times, for example:

"We considered that 'Well, we meet the [Ministry's] three-month target', but the PLC reminded us that waiting times for cancer diagnosis and treatments were excessively anxious. So we have met our medical imaging team. We have been working to further reduce delays to ultrasound for suspected breast cancer (clinician manager, local level). 
When providers saw that something within their control was better for patientsthey were often motivated to solve the problem promptly.

"What we did - and this was agreed by the whole executive committee - was to ensure that for clients who now had go to another location for care, we would cover transportation. This was concretised by providing taxi coupons" (clinician manager, local level).

To improve access to community support services, one local committee worked to integrate a referencing tool to 20 community services in the organisation's electronic record system.

"These include transportation, psychological support, healthy lifestyles, maintenance of physical capacities, caregiver support, and more" (manager, local level).

Informants recognised that providers and patients struggled to address multiple wide-ranging priorities around what was needed to optimize the cancer trajectory. For example, as clinicians on one local committee discussed investment in a \$10 million linear accelerator:

"The PLC said 'after I was discharged home, I would have liked to be able to call the nurse.' That brought everyone back down to earth" (manager, local level).

Many clinicians and managers expressed that PLC need to be present on committees to raise issues that would otherwise go unnoticed: "if something is not named, it's as though it doesn't exist" on the agenda of decision-makers (clinician manager, local level). PLC participation "served as an important lever to put actions in place" (clinician manager, local level) and "forced providers to rethink their positions" (clinician, local level) when these diverged from PLC perspectives.

\section{Mechanism 2) Shaping opportunities to translate mandated PLC representation into meaningful participation}

There was no preconceived way of working with PLC in network governance structures: "we're learning how to swim once we're in the water" (policymaker, national level). The Cancer Directorate framework mandated that PLC be invited onto local committees, but provided little guidance around modalities or the roles and responsibilities PLC would assume. The Cancer Directorate and national committee looked to PLC for advice on how to shape these opportunities for PLC participation:

[I was] asked: "Would you and another PLC come with us to give the patients' viewpoint and help formalise the various committees where patient representatives will have a presence and fulfil the responsibilities we expect of them?" (PLC, national level).

Integrating PLC input into deliberations required learning on all sides. Some PLC had difficulty raising problems, felt their input was discounted, notably by physicians, who "felt they knew what was best" [PLC, national level]) or that there was little place for PLC contributions on the issues discussed. There were also 
difficulties recruiting PLC on some local committees. Certain PLC informants highlighted that committees were sometimes ill prepared to integrate them.

"When I attended the first local cancer committee meeting, I was the first to arrive and sat a one end of the table. When the others arrived, they sat at the other extremity, never asked me who I was and did not explain my role. At the end of the meeting I felt very alone and asked myself what I was doing there" (PLC, national committee).

Others considered the meetings were structured to make room for their specific contributions.

"I got an extraordinary welcome. 'So (they would ask), what do you think?' They gave me feedback on what I said. They informed me about follow-up. My name is on the agenda. The vocabulary was difficult at first but now it's fine" (PLC, local level).

PLC participation in local governance committees was enhanced by the establishment, part way through our study period, of a national PLC committee. It functioned as a community of practice, with representatives from each local network committee and the national committee. The idea came from a PLC on the National Coordinating Committee, who saw the need to provide a protected space where PLC could collectively reflect on issues arising within their respective committees. The Cancer Directorate confirmed the community of practice's official mandate as to promote communication and sharing of knowledge and experience in order to contribute to improving cancer care and services. It was also made responsible for developing supports for PLC on governance committees, and for providing input as requested into National Cancer Committee documents (29). Meeting two to three times per year, members pooled their experience of cancer care and ideas for improvement, and addressed challenges around participation in local committees, including the uneven reimbursement of expenses, the need for preparation, and discouragement among some PLC participants due to lack of feedback and progress on issues they raised.

PLC reported that they were better able to contribute to local committees as a result of their participation in this community of practice, a perception that was shared by clinical managers on local committees.

"What they (the PLC members on our committee) were saying was listened to because it resonated with what we were hearing from the national PLC committee" (clinical manager, local level).

Overall, the national PLC committee increased the confidence and skills of PLC participants, heightened their legitimacy at local level, and provided a national hub to work on common PLC priorities. The PLC community of practice identified physicians' skills in "breaking bad news" as a first shared priority, and a training program for physicians was developed for province-wide implementation. Providers on local committees regarded PLC reports of discussions they had in the community of practice as "a precious source of information about how care is experienced in the regions" (clinical manager, local level) that complemented professional perspectives.

One PLC described the network committees as a "mountainchain", providing a route for issues arising locally to make their way up to national level: "That makes it more difficult to pretend that everything is 
working well when in fact it isn't' (PTC, local level).

While national and local coordinating committees and the national PLC committee provide opportunities for participation, they live within a network where decision-making is perceived as highly centralized around the Cancer Care Directorate. A number of informants expressed a lack of mutual listening between committees and the Directorate, which "solicits input from the various committees, but does not act on their recommendations" (clinical manager, local level).

This central role enables the Directorate to embed PLC participation within network governance committees. However, it also appears to delimit PLC influence within the network and impede PLC participation in governance functions of resource distribution and monitoring of performance, which remain at Ministry level where opportunities for PLC participation are lacking.

As committees are not involved in resource allocation decisions, PLC have no opportunity to influence this governance function.

"She [the PLC]) makes us aware of issues, but as our local committee does not make resource allocation decisions, she is not involved in decision-making" (clinical manager, local level).

The central level also retains the role of defining and monitoring performance indicators in the network.

"We want to deploy the information system in cancer in order to perform a follow-up in real time, and to be proactive. We are working with finance, the archivists and others to develop a dashboard. It is up to us to develop this dashboard" (policymaker, national level).

PLC do not yet have access to these data, something regarded as an impediment to participating in governance.

"We don't have access to the network operational statistics and we need to if we want to fully contribute to analysis of what is done and suggest solutions that make sense" (PLC, national level).

\section{Mechanism 3) Recognizing PLC knowledge in decision- making}

PLC and provider informants at local level recognize that a collaborative approach is needed for PLC to be comfortable sharing their knowledge within committee discussions and for clinicians and managers to accept PLC input as valuable and constructive.

"Getting engaged within the organisation (...) to try to make things move positively, calmly, while being aware of constraints. Working with, not confronting. Trying to use constraints as levers [for improvement]..." (PLC, local level). 
PLC participation in decision-making was seen to help defuse conflict among providers on certain issues, enabling a better management of relationships between network actors: providers were less willing and able to defend their interests when these were misaligned with needs expressed by the PLC. Oftentimes, such discussions led to new understanding of what patient-centred quality care entailed.

"Often, when we talk about the hierarchy of service, doctors will say "But patients don't want to travel far. If we tell them they have to go to (City 1 ) for their surgery, they'll refuse". True, there are some who don't want to make the trip, but there are others who say 'If the best treatment is in Italy, I'll go there and for me that's no problem" (policymaker, national level).

A number of initiatives where PLC were most active revolved around improving people's ability to use services effectively. On local committees, PLC raised concrete issues they faced in meeting their needs. They also co-led a number of projects that served to improve patient ability to understand and negotiate both their cancer treatment and the system. In one local network, PLC and clinicians designed and provided group information sessions for patients starting treatment to help them understand the process, anticipate problems and know how to respond, a best practice then shared within the national PLC committee. Similar sessions for patients coming to the end of treatment were also under development:

"Patients are much better informed today and the system needs to reinforce their strengths and support their weaknesses" (clinical manager, local level).

Within local networks, work to design tumour-site-specific trajectories increased reliance on PLC experience, thereby enhancing their influence on the governance function of knowledge management. Trajectory design involves understanding, from the patient's perspective, all steps from investigation of a suspicious lesion to life beyond active treatment in order to coordinate among providers, set priorities and develop solutions. Indeed, only PLC have the entire vision of the trajectory. In this exercise, PLC were seen to have essential knowledge that clinicians, managers and administrators needed to work out collaborative relationships and eliminate barriers between services. Local networks employed a variety of strategies to work with PLC in trajectory design. In one, PLC members of local committees worked with staff to design surveys and conduct small group workshops of people with the specific cancer in question to clarify the current situation, and gain insight into barriers and how these might be eliminated. A large number of PLC were involved in the process,

"...which is very demanding for the people involved... but will ensure we're moving in the right direction given our local reality" (clinical manager, local level).

The PLC involved found it rewarding to both put their committee experience with clinicians and managers to work to engage other PLC, and apply their knowledge and insight to improve future patient experience.

"Mapping patient experience along a trajectory revealed gaps between the reality perceived by providers and that lived by patients. These contradictions encouraged providers to re-examine processes and priorities for improvement, and local context assumed greater importance. It also became evident that PLC participation needed to extend beyond hospitals to cover other steps in the care trajectory (clinical manager, local level). 


\section{Discussion}

This study reveals three mechanisms that interact to enable PLC participation in cancer network governance. However these mechanisms are not evenly activated in all parts of the network, nor for all governance functions.

First, the spread of PCC values, emphasized persistently by the Cancer Care Directorate, appears to give actors "a shared value system that will help them cooperate in a collective project" (26). PLC participation is a deliberate effort to operationalize 'governance through the patient's eyes' within network structures. It appears as a manifestation of PCC values, while also shaping the way 'person-centred' is conceived in context (36). Common values underpin relational aspects of governance in the network (37). PLC participation in committees at local level is seen to enhance mutual recognition of each actor's contribution, and motivates development of collaborative governance capacities within organisations (38).

Second, the structures mandated by the Cancer Care Directorate open up opportunities for participation that are then shaped to enhance relationships among actors and among local networks. Interaction between national and local levels enables better alignment between "policies and capabilities found at the strategic and operational levels of health systems" (38). While local committee members characterise their relationship with the national level as very top down, participation offers an opportunity to connect with counterparts in other organisations and form 'parallel networks' where they can collaborate on specific issues. Communities of practice supported by the Cancer Care Directorate further increase network interaction among providers and PLC as well as between PLC. These multiple relational spaces - areas of interaction and inclusion to develop collective action (39) - in collaborative governance contribute to knowledge exchange and innovation among particular actor-groups, and to breaking down "invisible walls" between actors from different groups within the network (40). Rodriguez and Denis' (41) describe interorganisational collaboration as paradoxical because it combines autonomy and interdependence. The combination of community of practice and committee structures may be seen as a way to accommodate this paradox: work together in a spirit of "collective learning" (42) to identify problems and interdependencies, then coordinate within actor-sets to see how each can best contribute to a collective solution.

The third mechanism sees PLC knowledge recognised in decision-making, as it supplements and aligns with knowledge of other actors to promote collective action (43). This mechanism is most evident in areas such as trajectory design, post-treatment supports and patient information and education that are highly dependent on PLC perspectives and where provider actors recognise their own knowledge gaps. The creation of a community of practice where PLC from local committees can assemble and exchange knowledge increases PLC confidence to participate in governance as well as provider appreciation for PLC contributions.

\section{PLC participation and governance functions}


Governance functions refer to various practices linking mobilisation of the capacities of network actors to the achievement of collective goals (26). The mechanisms at work in the Quebec cancer network facilitate PLC participation in some but not all governance functions. Opportunities to embody and clarify values of person-centred care facilitate participation in shaping network vision and mission; the various committees support PLC participation in managing knowledge and relationships within and across network levels. However, while the Cancer Care Directorate nurtures PLC participation by mandating these structures, it also limits PLC participation to governance functions that lie within the purview of these structures. Two are notably absent: monitoring and resource allocation. A logical evolution in the network may be to better integrate PLC into these functions at higher levels of governance.

Local and national committees have little influence on resource allocation decisions, which presents a challenge to acting on PLC participation, especially when (as in efforts such as trajectory design), a set of resources outside the local organisation is required to meet patient needs. Monitoring functions are also closely guarded and tied to a narrower view of cancer care than is held by PLC. The performance indicators used across the network are selected by a closed group at Ministry level, which remains sheltered from network interactions. The lack of PLC participation here raises a contradiction that is likely to increase tension in the network over time. Notions of value in PCC may differ from those arising from government concerns such as health economics (44), and some describe value-based care and PCC in opposition to one another (45). In this sense, indicators of patient experience could, if they moved in opposite directions to cost control or efficiency indicators, pose problems to national network leaders. Brown, looking at Ontario's cancer system, considers that current indicators used to measure aspects of quality such as patient experience, value and equity "do not match the scope of these goals" and "include some of the poorest ratings" (46). Within the Quebec Cancer Network, there appears to be some openness to greater PLC involvement in monitoring, if not developing, indicators. None of the local networks included in our study were tracking actions and decisions taken in response to PLC participation.

Our findings reveal that local and national levels are mobilising PLC capacities in the accomplishment of network governance. In terms described by Provan and Kenis (47), the Quebec Cancer Directorate can be seen as a "network administrative organisation" that governs the network externally. However it also acts as a lead organisation and broker, playing a key role in coordinating and sustaining the national network (47) and orchestrating the activity of local committees, which in turn serve as "lead organisations" to coordinate local network actors. Within this dynamic, network governance functions are assumed by a distributed set of actors, sometimes filtering down hierarchically, but also emerging from organisational and operational levels and filtering across local networks.

\section{Implications for practice and research}

Langley and Denis (48), looking at innovations requiring participation by heterogeneous actors, consider "that the distributed nature of the benefits and costs of any practice needs to be understood if one wants to implement change" (48). PLC participation appears in our study as a promising means of ensuring that the benefits and costs to patients of a given practice become part of this negotiation. However, our in-depth

Page $12 / 20$ 
study over six years reveals that PLC participation in network governance is itself a "wicked problem". In all likelihood, it will become even more complex as participation matures, considering the paradox of interdependency and autonomy in decision-making, as well as the emerging tension highlighted by Brown (see above) between patient experience and other measures of performance. In practice, results of our study suggest that PLC participation in governance takes shape through a balance between normative prescription from the network lead and support for learning, collaboration and constant practice adaptation.

There is increasing interest in enhancing patient partnership in care and citizen contributions to coproducing healthcare services (25). In Quebec, a university-led initiative is seeking to move beyond PCC and integrate patients as partners in care, health professional education and health research (49). In Europe, a major project (COGOV) is now exploring how public agencies can "exploit the drivers - and overcome the barriers - to the co-production and co-creation of innovative public value outcomes" by recognizing citizen input into the process of public governance (17). Our study suggests that this ambition goes hand in hand with network integration and governance structures that bring actors, including PLC, together so they can figure out how each might tailor their contribution to best meet collective goals.

\section{Study strengths and limitations}

This case study provides an unprecedented exploration of PLC participation as it evolves in network governance structures at multiple levels. It contributes to filling an important knowledge gap around the sustainability of patient participation (50), as well as furthering our understanding of factors that impact the participation of PLC in integrated cancer network governance dynamics. This aligns with the collaborative governance framework (21) and reveals it as a promising route to further explore the participation of PLC in cancer networks.

A major strength of this study is the detailed data collected over six years that enables unprecedented exploration of a complex phenomenon: PLC participation in network governance. While research on partnering with patients in care and quality improvement initiatives has increased over the last two decades, the participation of PLC in cancer network governance has received less attention. Informed by conceptual frameworks on governance (26) and collaborative governance (21), adapted to cancer care, the present study offers evidence on how PLC participation in governance functions takes shape though the activation of certain mechanisms. In Quebec, PLC participation is seen to contribute to shifting top-down decision-making cultures to shared leadership that includes PLC (51). Our results suggest that the formalisation of committees at national and local level, and, specifically the National PLC Committee, acts as a starting point in complex system change. The study highlights challenges regarding the governance functions of resource allocation and performance monitoring in the network context generally, and specifically with regard to PLC participation.

Activation of the mechanisms we identify is highly context dependent, which limits the transferability of our findings, as we do not explore the interaction between context and mechanism in detail. But by focussing on underlying mechanisms revealed in patterns emerging from natural settings, and on linkages between 
these and governance functions in action, researchers may assess the transferability of our findings to other initiatives aimed at achieving PLC participation in national cancer programs. An important goal for future research would be to discover why a specific mechanism (28) is activated (or not) in order to build a theory of the intervention (PLC participation in network governance). Studying context-mechanism-outcome configurations (52) appears a logical direction for this type of explanatory research.

Data collection was completed a few months prior to the global Covid-19 pandemic, which had an immediate and important adverse effect on the context for activating the mechanisms we identify, specifically opportunities for participation and possibilities for knowledge exchange. It is hoped that our findings will help guide the adjustment phase by challenging actors to find ways of activating mechanisms that support PLC participation in new forms.

Finally, seeking the active mechanisms of PLC participation is value-laden and implies a critical epistemological posture about how and why it may be translated from the idea prescribed by policymakers to practice. We find that PCC as a network value and objective is a mechanism for driving PLC participation, but also that PLC participation serves to clarify what PCC means in different contexts.

\section{Conclusions}

There is growing political will to engage patients in governance structures at all levels of health systems to increase responsiveness to evolving needs $(8,53)$. The Quebec Cancer Directorate's adoption of PCC as an objective, and its mandate that PLC be included in network governance structures, provided a unique opportunity to advance knowledge on the challenges and opportunities for translating political will into better care. The long study period and wide range of informants increase our confidence in findings that 1) emphasizing patient-centred care as a network objective, 2) shaping opportunities for PLC contributions and 3) recognizing PLC knowledge in decision-making are important means of increasing the legitimacy of PLC participation in the governance of network-based cancer care. The recursive mechanisms identified here are important to the structuration of PLC participation in dynamics of collaboration within and between levels of governance. Findings offer new theoretical and practical insight into both network governance and mechanisms that enable PLC participation to tailor and institutionalise PCC within the network and pave the way to real partnership. Structuring the role of PLC in national and local governance committees narrows governance divides between levels, which in turn appears likely to contribute to integrated cancer care.

\section{List Of Abbreviations}

PLC people living with and beyond cancer

MSSS Ministère de la Santé et des Services sociaux; in English: Ministry of Health and Social Services PCC patient-centred care

\section{Declarations}




\section{Ethics approval and consent to participate}

This study received approval from the Ethics Review Board (MP-HCLM-14-010; MP-04-2019-316) and all participants signed an informed consent form.

\section{Consent for publication}

Not applicable.

\section{Availability of data and materials}

Details on the data collection and analysis grids are available upon request from the lead author (DT). Ethics considerations prevent sharing of the raw data.

\section{Competing interests}

None to declare.

\section{Funding}

This research was funded by the Fonds de recherche Québec - Santé (2014-2018; Grant no 27193), and the Oncopole Partnership, Société de recherche sur le cancer, Fonds de recherche Québec - Santé (2018-2021, Grant no 265874). The funding bodies evaluated the scientific value and feasibility of the research protocol. They were not involved in the research process, or in reviewing or approving the manuscript.

\section{Authors' contributions}

All authors made substantial contributions to this article. DT and NT designed the research project and led the team throughout the six-year study. DT, NT and LL contributed to the acquisition of data. LL and SU undertook the coding of data, with LL contributing to early stage analysis. SU, DT and NT undertook final analysis of data. DT, NT, SU, KB and MPP collaborated on the interpretation of data and results. SU and DT led the drafting of the article, with input from NT, KB, MPP and LL. All authors approved the submitted version.

\section{Acknowledgements}

We thank the actors from the various local cancer networks and national agencies in Quebec who participated in this research. 


\section{References}

1. Fashoyin-Aje LA, Martinez KA, Dy SM. New patient-centered care standards from the commission on cancer: Opportunities and challenges. The Journal of Supportive Oncology. 2012 May;10(3):107-11.

2. Evans J, Matheson G, Buchman S, MacKinnon M, Meertens E, Ross J, et al. Integrating cancer care beyond the hospital and across the cancer pathway: A patient-centred approach. hcq. $2014 \mathrm{Dec}$ 23;17(SP):28-32.

3. McConigley R, Platt V, Holloway K, Smith J. Developing a sustainable model of rural cancer care: The Western Australian Cancer Network project: A model of rural cancer care. Aust J Rural Health. 2011 Dec;19(6):324-8.

4. Haward RA. The Calman-Hine report: a personal retrospective on the UK's first comprehensive policy on cancer services. The Lancet Oncology. 2006 Apr;7(4):336-46.

5. Ziebland S, Coulter A, Calabrese D, Locock L, editors. Understanding and using health experiences: Improving patient care. Oxford: Oxford University Press; 2013.

6. Baker GR. Evidence boost: A review of research highlighting how patient engagement contributes to improved care. Ottawa: Canadian Foundation for Healthcare Improvement; 2014. http://citeseerx.ist.psu.edu/viewdoc/download?doi=10.1.1.676.3590\&rep=rep1\&type=pdf. Accessed July 20, 2020.

7. Bombard Y, Baker GR, Orlando E, Fancott C, Bhatia P, Casalino S, et al. Engaging patients to improve quality of care: A systematic review. Implementation Science. 2018;13(1):1-22.

8. Epstein RM, Fiscella K, Lesser CS, Stange KC. Why the nation needs a policy push on patient-centered health care. Health Aff (Millwood. 2010;29(8):1489-95.

9. Bodolica V, Spraggon M, Tofan G. A structuration framework for bridging the macro-micro divide in health-care governance. Health Expectations. 2016 Aug;19(4):790-804.

10. Castro EM, Van Regenmortel T, Vanhaecht K, Sermeus W, Van Hecke A. Patient empowerment, patient participation and patient-centeredness in hospital care: A concept analysis based on a literature review. Patient Education Counseling. 2016 Dec;99(12):1923-39.

11. MSSS. Ensemble, en réseau, pour vaincre le cancer: plan directeur en cancérologie [Internet]. Québec: Santé et services sociaux Québec; 2013. http://www.deslibris.ca/ID/237988. Accessed July 20, 2020.

12. Union for International Cancer Control. World Cancer Declaration. New York: Union for International Cancer Control; 2013.

https://www.uicc.org/sites/main/files/atoms/files/131119_UICC_WorldCancerDeclaration_2013_1.pdf. Accessed July 20, 2020.

13. WHO. Framework on integrated people-centred health services. WHO; 2016. https://apps.who.int/gb/ebwha/pdf_files/WHA69/A69_39-en.pdf?ua=1\&ua=1. Accessed July 20, 2020.

14. Isett KR, Mergel IA, LeRoux K, Mischen PA, Rethemeyer RK. Networks in public administration scholarship: Understanding where we are and where we need to go. Journal of Public Administration Research and Theory. 2011 Jan 1;21(Supplement 1):i157-73. 
15. Rittel H, Webber M. Dilemmas in a general theory of planning. Policy Sci. 1973;4:155-69.

16. Ferlie E, Fitzgerald L, McGivern G, Dopson S, Bennett C. Making wicked problems governable? The case of managed networks in health care. Oxford: Oxford University Press; 2013.

17. Ferlie E, Pegan A, Pluchinotta I, Shaw K. Co-production and co-governance: Strategic management, public value and co-creation in the renewal of public agencies across Europe. European Union; 2019 p. 61.

18. Hatchuel A. Prospective et gouvernance: quelle théorie de l'action collective. In: Prospective pour une gouvernance démocratique. Paris: Éditions de l'Aube; 2000. pp. 29-41.

19. van Rensburg AJ, Rau A, Fourie P, Bracke P. Power and integrated health care: Shifting from governance to governmentality. International Journal of Integrated Care. 2016 Sep 14;16(3):17.

20. Addicott R, McGivern G, Ferlie E. Networks, organizational learning and knowledge management: NHS cancer networks. Public Money Management. 2006;26:87-94.

21. Emerson K, Nabatchi T. Collaborative Governance Regimes. Georgetown University Press; 2015.

22. Tremblay D, Touati N, Poder T, Vasiliadis H-M, Bilodeau K, Berbiche D, et al. Collaborative governance in the Quebec Cancer Network: A realist evaluation of emerging mechanisms of institutionalization, multilevel governance, and value creation using a longitudinal multiple case study design. BMC Health Serv Res. 2019 Dec;19(1):752.

23. Souliotis K, Peppou L-E, Tzavara C, Agapidaki E, Varvaras D, Buonomo O, et al. Cancer patients' organisation participation in heath policy decision-making: a snapshot/cluster analysis of the EU-28 countries. BMJ Open. 2018 Aug;8(8):e018896.

24. Ferlie E, Mcgivern G, FitzGerald L. A new mode of organizing in health care? Governmentality and managed networks in cancer services in England. Social Science Medicine. 2012 Feb;74(3):340-7.

25. Brown A. The challenge of quality improvement at the system level: Whither CCO? hcq. 2014 Dec $23 ; 17(\mathrm{SP}): 48-51$.

26. Denis J-L, Champagne F, Pomey M-P, Préval J, Tré G. Toward a framework for analysis of governance in healthcare. Preliminary report presented to the Canadian Council on Health Service Accreditation, Université de Montréal, 2005.

27. Tremblay D, Touati N, Roberge D, Breton M, Roch G, Denis JL, et al. Understanding cancer networks better to implement them more effectively: A mixed methods multi-case study. Implementation Science. 2016;11(1):39.

28. Astbury B, Leeuw FL. Unpacking black boxes: Mechanisms and theory building in evaluation. American Journal of Evaluation. 2010 Sep;31(3):363-81.

29. MSSS. Les personnes touchées par le cancer: partenaires du réseau de cancérologie : cadre de référence. Québec: Ministère de la Santé et Services sociaux du Québec; 2017 https://publications.msss.gouv.qc.ca/msss/fichiers/2016/16-902-23W.pdf. Accessed July 20, 2020.

30. Stake RE. Multiple case study analysis. New York: Guilford Press; 2013. 342 p.

31. Guest G, Namey E, Mitchell M. Collecting qualitative data: A field manual for applied research. Thousand Oaks: SAGE Publications; 2013. 
32. LePan C. Review of QDA Miner. Social Science Computer Review. 2013;31(6):774-8.

33. Belotto MJ. Data analysis methods for qualitative research: Managing the challenges of coding, interrater reliability, and thematic analysis. The Qualitative Report. 2018;23(11):2622-33.

34. Miles M, Huberman A, Saldana J. Drawing and verifying conclusions. In: Qualitative Data Analysis. Thousand Oaks: Sage Publications; 2014. pp. 293-322.

35. Tong A, Sainsbury P, Craig J. Consolidated criteria for reporting qualitative research (COREQ): a 32-item checklist for interviews and focus groups. International Journal for Quality in Health Care. 2007 Sep 16;19(6):349-57.

36. Waters RA, Buchanan A. An exploration of person-centred concepts in human services: A thematic analysis of the literature. Health Policy. 2017;121(10):1031-9.

37. Willem A, Gemmel P. Do governance choices matter in health care networks?: an exploratory configuration study of health care networks. BMC Health Serv Res. 2013;13(1):1.

38. Denis J-L, Usher S. Governance must dive into organizations to make a real difference: Comment on 'Governance, government, and the search for new provider models'. International Journal of Health Policy and Management. 2016 Jul 3;6(1):49-51.

39. Kellogg KC. Operating room: Relational spaces and microinstitutional change in surgery. American Journal of Sociology. 2009 Nov;115(3):657-711.

40. Liberati EG, Gorli M, Scaratti G. Invisible walls within multidisciplinary teams: Disciplinary boundaries and their effects on integrated care. Social Science Medicine. 2016 Feb;150:31-9.

41. Rodríguez C, Langley A, Béland F, Denis J-L. Governance, power, and mandated collaboration in an interorganizational network. Administration Society. 2007 Apr;39(2):150-93.

42. Wenger E. Communities of practice: Learning as a social system. Systems thinker. 1998;9:5:2-3.

43. Pomey M-P, Hihat $H$, Khalifa M, Lebel P, Néron A, Dumez V. Patient partnership in quality improvement of healthcare services: Patients' input and challenges faced. Patient Experience Journal. 2015;2(1):2942.

44. Porter M, Teisberg E. Redefining health care: Creating value-based competition on results. Harvard Business School Press; 2006.

45. Tseng EK, Hicks LK. Value-based care and patient-centered care: Divergent or complementary? Curr Hematol Malig Rep. 2016;11(4):303-10.

46. Brown A. The challenge of quality improvement at the system. Whither CCO? Healthcare Quarterly. 2015;14(Special Issue):48-51.

47. Provan KG, Kenis P. Modes of network governance: structure, management, and effectiveness. Journal of Public Administration Research and Theory. 2007 Jun 29;18(2):229-52.

48. Langley A, Denis J-L. Beyond evidence: the micropolitics of improvement. BMJ Quality \& Safety. 2011 Apr 1;20(Suppl 1):i43-6.

49. Dumez V, Pomey M-P. From medical paternalism to care partnerships: A logical evolution over several decades. In: Patient engagement: How patient-provider partnerships transform healthcare organizations. Palgrave;C Monograph Series: Organisational Behaviour in Healthcare; 2019. pp. 9-16. 
50. Berger Z. Metrics of patient, public, consumer, and community engagement in healthcare systems: How should we define engagement, what are we measuring, and does it matter for patient care? Comment on 'metrics and evaluation tools for patient engagement in healthcare organization- and system-level decision-making: A systematic review'. International Journal of Health Policy and Management. 2018 Oct 2;8(1):49-50.

51. Tremblay D, Latreille J, Bilodeau K, Samson A, Roy L, L'Italien M-F, et al. Improving the transition from oncology to primary care teams: A case for shared leadership. JOP. 2016 Nov;12(11):1012-9.

52. Pawson, Ray R, Tilley N. Realistic evaluation. London: Sage; 1997.

53. Gagliardi AR, Legare F, Brouwers MC, Webster F, Wiljer D, Badley E, et al. Protocol: developing a conceptual framework of patient mediated knowledge translation, systematic review using a realist approach. Implement Sci. 2011;6:1-5.

\section{Figures}

\begin{tabular}{|l|}
\hline National PLC committee \\
Brings together all PLC \\
representatives from the \\
coordinating committees of local \\
organisations, PLC \\
representatives from the \\
National Coordinating \\
Committee of the Cancer Care \\
Directorate (CCD) and their \\
mentors in a form of community \\
of practice. It is co-led by a \\
professional designated by the \\
CCD and a PLC representative \\
selected by the leaders of the \\
National Coordinating \\
Committee.
\end{tabular}

National Coordinating Committee Includes one or more PLC representatives. They are paired with a committee member (mentor).
Organisation (local)
Coordinating Committee Includes one or more PLC representatives. They are paired with a committee member (mentor).

Figure 1

PLC representation in the Quebec Cancer Care Network PLC: people living with and beyond cancer; Cancer Care Directorate (in French: Direction générale de cancérologie) 


\section{Supplementary Files}

This is a list of supplementary files associated with this preprint. Click to download.

- Additionalfile2COREQchecklist.pdf

- Additionalfile1Focusgroupandinterviewguide.pdf 